\title{
Does the environment constrain avian sound localization?
}

\author{
OLE N. LARSEN \\ Centre for Sound Communication, Institute of Biology, University of Southern Denmark \\ Campusvej 55, DK-5230 Odense M, Denmark \\ Manuscript received on January 15, 2004; accepted for publication on February 5, 2004.
}

\begin{abstract}
A bird needs to keep track not only of social interactions of conspecifics but also of their changing locations in space by determining their directions and distances. Current knowledge of accuracy in the computation of sound source location by birds is still insufficient, partly because physiological mechanisms of few species are studied in well defined laboratory settings, while field studies are performed in a variety of species and complex environments. Velocity gradients and reverberating surfaces may conceivably induce inaccuracy in sound source location (mainly elevation) by distorting the directional cues. However, most birds possess an inherently directional pressure difference receiver, which enhances the directional cues (mainly azimuth), and a computational mechanism in their auditory pathways to suppress echoes of redirected sound.
\end{abstract}

Key words: directional hearing, elevation, azimuth angle, precedence effect.

\section{INTRODUCTION}

A sound recording of the avian morning choir in a forest or the vocalizations from a colony of sea gulls is a chaos of superimposed sounds when the recording is done with one omnidirectional microphone. In contrast, a human observer automatically perceives an acoustic environment composed of separate sound objects (i.e. vocalizing birds) when listening from the same position as the microphone. The reason is that the human observer using his directional hearing and high level auditory computations is able to perform an auditory scene analysis (Bregman 1990). Most of the time the human localization of sound objects is rather precise, although casual observation indicates that it may sometimes be way off, especially in a forest environment. Judging from their reactions, birds also seem to be aware of the whereabouts of vocalizing conspecific friends and foes but the mechanisms involved and the pre-

E-mail: onl@biology.sdu.dk cision, with which they perform an auditory scene analysis, are not fully understood (for references see e.g. Klump 2000).

In order to localize a sound source, a listening bird needs to compute three spatial coordinates: the horizontal angle, or azimuth (relative to the direction of the beak), the vertical angle, or elevation (above or below the position of the listening bird), and the distance from listener to singer. The elevation coordinate seems important mainly at short distances and probably does not require a high degree of accuracy but nothing is known about mechanisms of its computation except for auditory specialists such as the Barn Owl Tyto alba (Konishi 1993). In contrast, much behavioral work has recently been performed on elucidating the accuracy and the cues by which birds compute the distance coordinate, a process known as 'ranging' (review by Naguib and Wiley 2001). Sound signal degradation with distance seems to play a major role in ranging but quantifica- 
tion of sound degradation has rarely been correlated with perceptual abilities and in certain types of habitat birds may use a simple measure of sound intensity of low frequency sounds as the ranging cue (Nelson 2002, 2003). To territorial species a gross ranging categorization may suffice in most behavioral situations: the vocalizing bird is close, it is located inside the territory, or it is beyond the territory borders. By far the most important spatial coordinate to the bird seems to be the azimuth angle, which intuitively requires a high degree of precision at all distances and is computed by the bird's directional hearing from time and intensity cues (see e.g. Klump 2000).

The computation of all three spatial coordinates is subject to some inaccuracy. This means that the listening bird often computes a position in space somewhat different from the actual one. In some cases, such as the auditory specialist the Barn Owl (and a number of other owl species) striking on a mouse on the laboratory floor, this inaccuracy is in the centimeter range for all three coordinates (Payne 1971). Marsh hawks have been reported to compute azimuth with an accuracy of as little as about $2^{\circ}$ (the minimum resolvable angle) in behavioral tests (Rice 1982). For birds with no obvious auditory specialization there is a larger inaccuracy, but evidence on order of magnitude from observations in the field is not in accordance with laboratory observations. For instance, it has been shown in a recent very comprehensive field study that Eastern Towhees Pipilo erythrophthalmus compute the azimuth angle of a sound source with an accuracy of $5^{\circ}-9^{\circ}$ (Nelson 2002). Other songbirds and small parrots tested in a psycho-acoustic setup in the laboratory, however, need a $23^{\circ}-28^{\circ}$ azimuth separation of sound sources to classify them as located separately (Park and Dooling 1991).

What could possibly induce uncertainty in a listening bird's computation of the spatial coordinates of a vocalizing bird? From a naïve point of view there are two major possible sources of uncertainty: (1) the listening bird's directional hearing is inaccurate because of limitations in the directional sensitivity of the ears and/or in the computational circuits of the brain; (2) the acoustical cues reaching the bird provide inaccurate information about the location. Below we shall investigate only the inaccuracy in computation of the directional coordinates, while interested readers are referred to Naguib and Wiley (2001) for a discussion of the computation of the distance coordinate.

\section{INACCURACY IN DIRECTIONAL COMPUTATION}

Like all other animals possessing a sense of hearing birds must construct the external acoustic world by computations based on minute sound pressure variations at their ears. A sound signal will arrive earlier at one ear (the ipsilateral ear) than at the other ear (the contralateral ear) unless the sound source is located in the median plane of the bird's head. The difference in time of arrival at the two ears (of both the onset envelope and any later variation) constitutes one major directional cue, the interaural time difference, ITD. The avian auditory system seems to process this ITD information from the ears according to Jeffress' (1948) coincidence detector model. Recently, this textbook view has been slightly modified as it has been shown that GABA inhibition fine tunes the coincidence detection in birds (Grothe 2003) creating a topological representation of azimuthal space in the auditory midbrain and optic tectum.

If a sound source is moved from the median plane (azimuth angle $0^{\circ}$ or $180^{\circ}$ ) to a position on the line passing through the ears (azimuth angle $90^{\circ}$ or $270^{\circ}$ ) ITD can be expected to vary from $0 \mu$ s to $53 \mu$ s between the ears of a small songbird with a head width of $12 \mathrm{~mm}$ (Klump 2000). For comparison, the head width of a human adult is typically about $170 \mathrm{~mm}$ and the maximum ITD about $600 \mu \mathrm{s}$, which allows for our fine resolution of azimuth angles. This order of magnitude difference between maximum human and bird ITD has supported the idea that birds exploit the air-filled passage connecting their middle ears, the interaural canal, for computation of azimuth angles (Fig. 1).

According to this model sound will arrive at the ipsilateral ear first and move the eardrum. The 


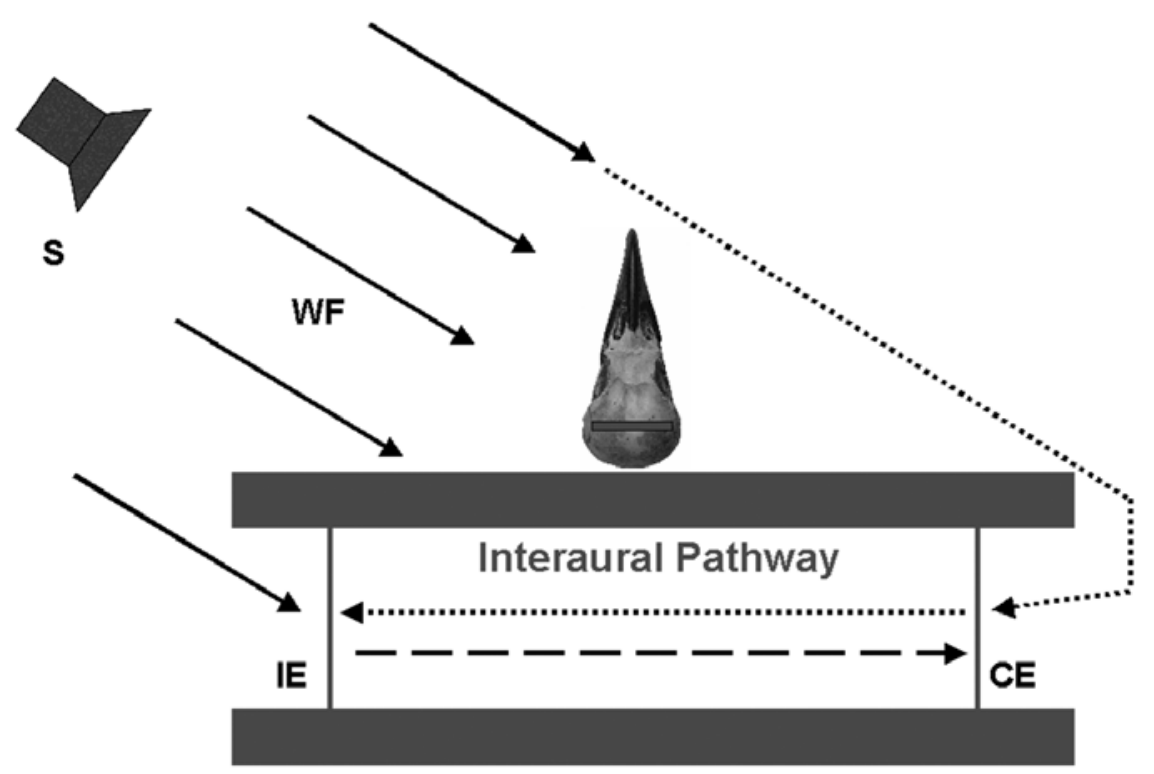

Fig. 1 - Sound transmission through the interaural canal turns the bird ears into coupled and inherently directional pressure difference receivers. The speaker located at an azimuth angle of $45^{\circ}$ emits a sound wave, which reaches the external surface of the ipsilateral eardrum, the movement of which transmits sound through the interaural canal. The transmitted sound is delayed and attenuated relative to the impinging sound. The same sequence of events happens at the contralateral eardrum. The resulting movement of the two eardrums is determined by the net force working on their respective internal and external surfaces, here indicated by oppositely directed arrowheads. Inset shows the approximate position of the interaural canal in the skull of a Hooded Crow Corvus cornix. S: Speaker; WF: wave front; IE: ipsilateral ear; CE: contralateral ear.

eardrum movement will transmit sound through the interaural canal and exert a force on the internal surface of the contralateral ear. The resulting movement of the contralateral eardrum will be determined by the difference between the force acting on the internal surface and that exerted on the external surface by the sound wave, which in the meantime has also reached the contralateral ear. However, the net movement of the contralateral eardrum also transmits sound in the opposite direction through the interaural canal and exerts a force on the internal surface of the ipsilateral eardrum. This is possible according to the principle of linear superposition. Therefore, according to this view the two ears in a complicated way act as coupled pressure difference receivers. Now ITD of the eardrum vibrations is different from that defined by the time of arrival to the entrances of the auditory meatuses. It can be shown mathematically (and substantiated by binaural measurements of cochlear microphonics) that this arrangement enhances ITD of low frequency sounds by a factor 2-3 but approaches the time-ofarrival ITD at high frequencies (Calford and Piddington 1988). Later studies using different methods (laser vibrometry) have failed to find a functional interaural canal (Klump and Larsen 1992). However, Ketamine anaesthesia may cause some birds to stop ventilating their middle ears. The result is that the eardrums are "sucked in" towards the middle ears and change their mechanical properties such that they hardly transmit any sound through the interaural canal (Larsen et al. 1997). When the measurements are repeated with the interaural canal artificially vented substantial variation in eardrum vi- 
bration amplitude with azimuth is observed (Larsen, Dooling and Michelsen, in prep.). The difference in vibration amplitudes of the two eardrums of Budgerigars Melopsittacus undulatus, for instance, is increased by $2-4 \mathrm{~dB}$ relative to that caused by diffraction around the head for sound frequencies of $2-4 \mathrm{kHz}$ and at a sound source azimuth angle of $30^{\circ}$. This vibration amplitude difference, by the way, constitutes the other major directional cue, the interaural intensity difference, IID.

However, the role of the interaural canal in avian directional hearing is by no means settled (see Klump 2000) and different bird species may use interaural transmission to different degrees. Auditory specialists like the Barn Owl Tyto alba, for instance, possess an interaural canal and yet no interaural transmission takes place (Moiseff and Konishi 1981). The properties of the few interaural canals investigated so far differ much but the physical basis of these differences is not understood. Systematic theoretical analysis (Michelsen and Larsen, in prep.) shows that sound transmission through the interaural canal in itself does not ensure useful cues, since proper phase and amplitude relationships must exist between the sounds acting on the internal and external surfaces of the eardrums. The optimum properties of sound transmission thus depend on the bird's head width and shape and on the sound frequency.

Because of its interaural-canal-coupled pressure difference receiving ears a bird like the Budgerigar may have a maximum ITD of $200 \mu \mathrm{s}$ (instead of only $100 \mu \mathrm{s}$ ) and a maximum IID of $5 \mathrm{~dB}$ (instead of $2 \mathrm{~dB}$ ) at $1 \mathrm{kHz}$. However, we are ignorant about how big ITD and IID need to be to make the bird able to reliably compute the azimuth angle in a complex real world environment.

\section{AMBIGUITY OF DIRECTIONAL CUES}

When a plane progressive sound wave reaches layers of air with different sound velocities it will bend away from layers of higher velocity and towards layers of lower velocity. This phenomenon is known as refraction. During the day a temperature gradi- ent in the air is often formed and decreases rapidly with height above ground over the first few meters and then by about $1^{\circ} \mathrm{C}$ per $100 \mathrm{~m}$. Since sound velocity is proportional to air temperature this means that sound will be bent away from the ground (see e.g. Wiley and Richards 1982, Embleton 1996) and a listener located in a tree top some distance away from a singing bird may conceivably judge it to be located closer to the ground than it actually is. A similar refraction may arise for a sound signal propagating upwind (wind velocity increases with height above ground and subtracts from the sound velocity creating a gradient of lower net velocity with height above ground). It is doubtful, however, if refraction ever creates a problem for birds computing the direction to a sound source. Both temperature and wind gradients are unstable and rarely well defined. The standard deviation (SD) of wind velocity is typically one third of the mean and in a temperature gradient SD can easily reach more than $1^{\circ} \mathrm{C}(\mathrm{Em}$ bleton 1996), so there will probably frequently be time windows with correct information reaching the listening bird. In addition, such velocity gradients mainly distort the less important elevation information but not (or only slightly) the important azimuth information.

Sound reflecting surfaces such as tree trunks in a forest or rocks in rugged terrain probably present a much more serious problem than refraction for computing the true direction to the vocalizing bird. The sound signal emitted from the singer reaches the listener by the shortest direct path, which is often (i.e. with no refraction present) identical with a straight line between the two, but it is rapidly followed by echoes from reflecting surfaces. If the direct path is partly blocked, thus reducing the direct sound amplitude, but a large sound reflector is present in an unobstructed path outside the direct one then the listener may be tricked into judging the singer to be located behind the reflector. The largest, ever-present sound reflector is the ground and a prominent specular ground reflection is observed for singer and listener positions up to about four meters above ground, even over a typical tem- 
perate forest floor (Larsen and Andersen, unpubl.). However, the ground reflection will only distort the less important elevation coordinate, not the azimuth.

Tree trunks close to the receiver or along the sound propagation path will produce prominent echoes, which may give false information about sound source location. However, it has recently been shown in a psycho-acoustic laboratory setup that Budgerigars (and probably all other auditory nonspecialized birds) possess a computational mechanism for echo suppression, the so-called precedence effect (Dent and Dooling 2003a, b). If the bird receives an echo from a different azimuth angle less than $0.5 \mathrm{~ms}$ after the arrival of the direct wave, it will judge the sound source to be located somewhere between the two directions (fusion). If, however, the delay between direct wave and echo is between about 0.5 and $5 \mathrm{~ms}$ the bird will totally ignore the echo and only attend to the direction of the first wave (echo suppression). Only if the delay is larger than about $5 \mathrm{~ms}$ will the bird react as if it hears two separate sounds from different directions. A delay of $5 \mathrm{~ms}$ corresponds to a path length difference of about $1.7 \mathrm{~m}$ at $20^{\circ} \mathrm{C}$. Theoretically then, all horizontal positions, in which a reflector could produce this path length difference between the direct and the reflected sound, form an ellipse with the sender and receiver located in the two foci, which are again positioned $1.7 \mathrm{~m}$ from their respective ends of the ellipse. Reflections from tree trunks located inside this ellipse will have practically the same amplitude as that of the direct wave. However, they are ignored by the bird because of the precedence effect. Reflections from outside the ellipse will interfere with directional computation but the necessary spacing of large tree trunks ensures that their amplitudes are reduced. So far, it has not been tested whether the avian auditory system works like this in the real world.

Sound signals propagating through dense vegetation with multiple scattering suffer all sorts of degradation (e.g. Wiley and Richards 1982, Dabelsteen et al. 1993, Holland et al. 1998). However, we do not know whether and to what extent the degradation also includes directional cues. Studies of grasshoppers orienting towards conspecific sound signals have shown that directional amplitude cues (interaural intensity differences) become increasingly useless as the listening animals are positioned in progressively denser grass whereas the phase information is much more robust (see e.g. Michelsen and Rohrseitz 1995). Since the grasshopper ears are pressure difference receivers it may well be that the possession of such ears is an adaptation not only to small body size but also to the kind of habitat (Michelsen and Larsen in prep.). It remains to be seen whether similar conditions apply to birds living in dense vegetation.

Finally, there are special circumstances when the directional hearing seems very difficult or impossible. For instance, an incubating hole-nesting bird such as a female Pied Flycatcher Ficedula hypoleuca may be able to distinguish whether its mate is singing directly in front of the nest hole or somewhere behind the tree but probably no more than that (see Lampe et al. 2004).

\section{CONCLUSION}

We still need much information to make firm statements about the possible environmental constraints on avian sound localization. The interaural pathway seems to enhance the directional cues but we are ignorant about the magnitudes of interaural intensity and time differences required for the necessary computation of spatial coordinates in the cluttered, time-varying and complex real world environment. Refraction probably presents a minor problem and reflections from objects close to the listening bird or close to the direct sound propagation path can partly be ignored by auditory processing such as the precedence effect. However, birds located inside nest holes or receiving high-frequency signals such as the seet-alarm call probably are unable to compute directions. The elevation coordinate is assumed to be less important than the azimuth and distance coordinates but virtually no information about its importance and computation exists for birds with 
symmetrical ears, though intuitively it must be important for a territorial songbird to compute this coordinate in a forest habitat with tall trees.

\section{ACKNOWLEDGMENTS}

This work was supported by the Danish National Research Foundation to the Center for Sound Communication.

\section{RESUMO}

Uma ave necessita acompanhar não somente as interações sociais de seus co-específicos, mas também suas mudanças de posição no espaço, calculando suas direções e distâncias. O conhecimento atual sobre a precisão do cálculo da localização de fontes sonoras por aves é ainda insuficiente, em parte porque poucas espécies têm seus mecanismos fisiológicos estudados em condições de laboratório bem controladas, enquanto os estudos de campo são realizados em espécies diversas e ambientes complexos. Os gradientes de velocidade e as superfícies de reverberação podem teoricamente induzir imprecisões na localização das fontes sonoras (principalmente na vertical) pela distorção das referências direcionais. Todavia, a maioria das aves possui um receptor de diferença de pressão que reforça as referências direcionais (principalmente no azimute), assim como um mecanismo, na cadeia auditiva, que descarta os sinais de eco.

Palavras-chave: audição direcional, elevação (ângulo vertical), azimute, efeito de precedência.

\section{REFERENCES}

Bregman AS. 1990. Auditory scene analysis: The perceptual organization of sound. Cambridge, MA: MIT Press.

Calford MB and Piddington RW. 1988. Avian interaural canal enhances interaural delay. J Comp Physiol A 162: 503-510.

Dabelsteen T, Larsen ON and Pedersen SB. 1993. Habitat-induced degradation of sound signals: Quantifying the effects of communication sounds and bird location on blur ratio, excess attenuation, and signalto-noise ratio in Blackbird song. J Acoust Soc Am 93: 2206-2220.
Dent ML And Dooling RJ. 2003a. Investigations of the precedence effect in budgerigars: Effects of stimulus type, intensity, duration, and location. J Acoust Soc Am 113: 2146-2158.

Dent ML and Dooling RJ. 2003b. Investigations of the precedence effect in budgerigars: The perceived location of auditory images. J Acoust Soc Am 113: 2159-2169.

Embleton TFW. 1996. Tutorial on sound propagation outdoors. J Acoust Soc Am 100: 31-48.

Grothe B. 2003. New roles for synaptic inhibition in sound localization. Nature Neurosci 4: 540-550.

Holland J, Dabelsteen T, Pedersen SB and Larsen ON. 1998. Degradation of Wren Troglodytes troglodytes song: Implications for information transfer and ranging. J Acoust Soc Am 103: 2154-2166.

JEFFRESS LA. 1948. A place theory of sound localization. J Comp Physiol Psychol 41: 35-39.

KLumP GM. 2000. Sound localization in birds. In: Dooling RJ, FAy RR And Popper AN. (Eds), Comparative Hearing: Birds and reptiles. New York: Springer-Verlag, p. 249-307.

KLUMP GM AND LaRsen ON. 1992. Azimuthal sound localization in the European Starling (Sturnus vulgaris): I. Physical binaural cues. J Comp Physiol A 170: 243-251.

Konishi M. 1993. Neuroethology of sound localization in the owl. J Comp Physiol A 173: 3-7.

Lampe HM, Dabelsteen T, Larsen ON and PederSEN SB. 2004. Degradation of song in a species using nesting holes: the Pied Flycatcher Ficedula hypoleuca. An Acad Bras Cienc 76: 264-266.

LARsen ON, Dooling RJ And Ryals BM. 1997. Roles of intracranial air pressure on hearing in birds. In: Lewis ER, Long GR, Lyon RF, NARINs PM, STEELE CR And Hecht-Poinar E. (Eds), Diversity in auditory mechanics. Singapore: World Scientific, p. 11-17.

Michelsen A AND Rohrseitz K. 1995. Directional sound processing and interaural sound transmission in a small and a large grasshopper. J Exp Biol 198: $1817-1827$.

Moiseff A AND Konishi M. 1981. The owl's interaural pathway is not involved in sound localization. $\mathbf{J}$ Comp Physiol A 144: 299-304. 
Naguib M And WiLey RH. 2001. Estimating the distance to a source of sound: mechanisms and adaptations for long range communication. Anim Behav 62: 825-837.

NeLson BS. 2002. Duplex auditory distance assessment in a small passerine bird (Pipilo erythrophthalmus). Behav Ecol Sociobiol 53: 42-50.

Nelson BS. 2003. Reliability of sound attenuation in Florida scrub habitat and behavioral implications. J Acoust Soc Am 113: 2901-2911.

PARK TJ AND Dooling RJ. 1991. Sound localization in small birds: Absolute localization in azimuth. $\mathrm{J}$ Comp Psychol 105: 125-133.
Payne RS. 1971. Acoustic location of prey by Barn Owls (Tyto alba). J Exp Biol 54: 535-573.

Rice WR. 1982. Acoustical location of prey by the Marsh Hawk: adaptation to concealed prey. Auk 99: 403413.

Wiley RH and RichaRds DG. 1982. Adaptations for acoustic communication in birds: sound propagation and signal detection. In: Kroodsma DE AND Miller EH. (Eds), Acoustic Communication in Birds, Vol. 1. New York: Academic Press, p. 131-181. 